\title{
The Effect of Starvation on the Liver of Aphanius Dispar (Pisces; Cyprinodontidae): A Microscopic Study
}

\author{
Taher A. Ba-Omar*, Mariam Al-Amri, Jameela Al-Belushi and Reginald Victor
}

Department of Biology, College of Science, Sultan Qaboos University, P.O.Box: 36, PC 123, Al-Khod, Muscat,Sultanate of Oman. ${ }^{\star}$ Email: taher@squ.edu.om.

\begin{abstract}
Stress due to starvation is not an uncommon phenomenon in fresh- and brackish water fish living in arid environments. This study, a part of a larger investigation on the effects of stress due to starvation on the organ systems of Aphanius dispar, a cyprinodont fish in Oman, reports on the histopathological changes in the liver, using light and transmission electron microscopy. The hepatocytes showed structural and ultrastructural changes in response to 24,48 , 72 and 96 hours of starvation. The hepatocytes of the starved fish groups were characterized by a reduction in the size of their cells and their nuclei, chromatin condensation, loss of stored glycogen, large lipid droplets, wide intercellular spaces and the variable sizes of their mitochondria. Swirls of smooth endoplasmic reticulum (SER) were seen in some of the starved fishes, which may indicate their involvement in lipid metabolism and the breakdown of glycogen. This paper makes a further contribution to the understanding of the physiology of fish in arid zones.
\end{abstract}

Keywords: Aphanius dispar fish; Liver; Hepatocytes; Ultrastructure; Starvation; Arid zones.
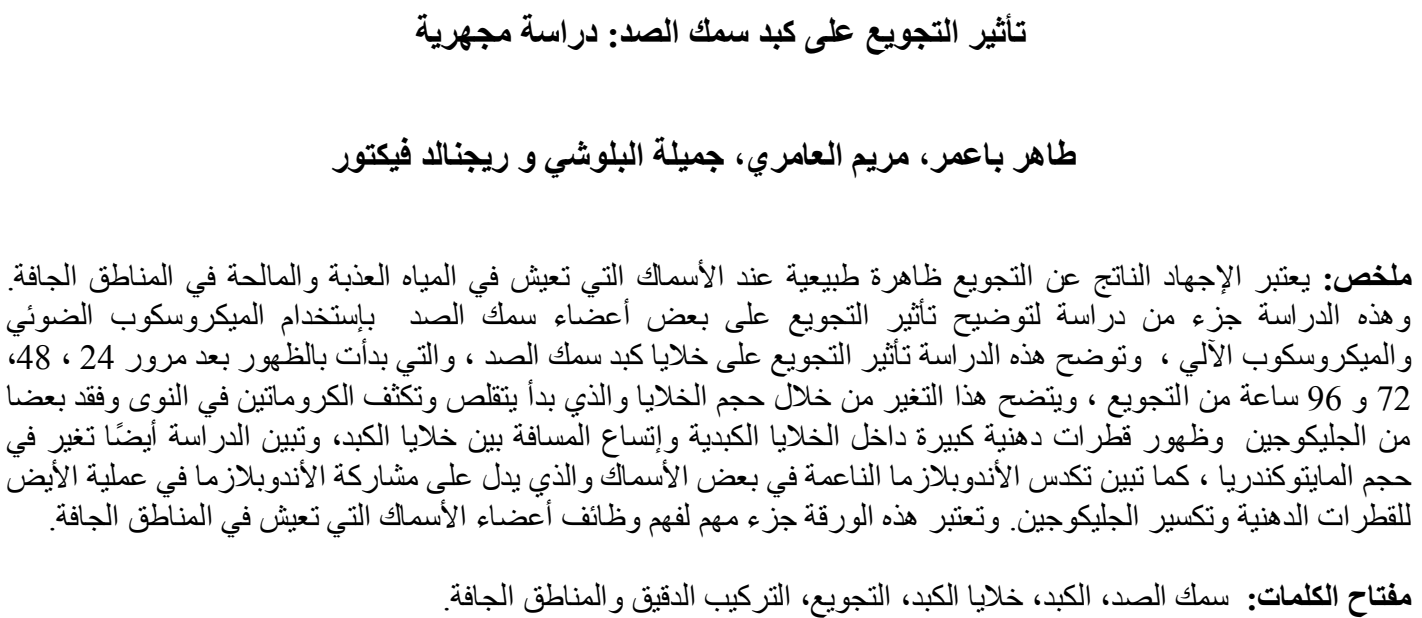

\section{Introduction}

$\mathbf{F}$ ish living in the shallow fresh- and brackish water pools of arid regions have to endure extremely hard environmental conditions. Apart from the physical and chemical conditions of the water, biological factors such as food availability exacerbated by intra- and inter-specific competition, could cause a level of stress requiring physiological adaptations to survive through periods of starvation of varying duration. These pools are potential breeding grounds for mosquitoes and other disease causing insects and their control primarily depends on the presence of their natural predators. Predators that are not capable of adapting to the physical and biological stress will become excluded competitively, and this is undesirable from the perspective of biological control.

Aphanius dispar (Rüppell 1828), a cyprinodont fish, is widely distributed in the fresh and brackish waters of the Middle East. It is an important, native bio-control agent of mosquito larvae [1]. It is a robust species that can adapt to a variety of habitats with differing water temperatures and stream flow, and to salinity ranges from that of freshwater to seawater and to other chemical parameters $[2,3,1,4]$. Reductions in food availability in $A$. dispar habitats can be due to a variety of factors including the physical and chemical conditions of the environment as well as the biological conditions such as primary and secondary production, population size and competition for resources [5]. 
Although some hardy fish like A. dispar may physiologically tolerate and adapt to short periods of starvation, detectable histopathological changes in organ systems are likely to occur. During starvation, there is a rapid depletion of energy forcing the animal to use its stored reserves in tissues and cells in order to stay alive [6].

Vertebrate liver is a storehouse of glycogen and lipids; it is one of the organs that is primarily affected by starvation. Teleost liver cells are sensitive to environmental changes such as those in water temperature, chemical quality and feeding conditions [5]. Histological studies describing the structural and ultrastructural changes of the liver in fish stressed by starvation are few. Of these, several studies have investigated the biochemical changes in liver tissue during starvation [7,8,9,10,11]. Ba-Omar et al. [12] studied the anatomy and histology of A. dispar, and investigated the ultrastructural changes in the epithelium of the stomach of A. dispar (Cyprinodontidae) due to stress from starvation. Here, we present a study of the liver of $A$. dispar when impacted by starvation using light and transmission electron microscopy.

\section{Materials and Methods}

Adult A. dispar specimens were collected from small fresh-water ponds near Sultan Qaboos University Campus, Al Khod, in the Sultanate of Oman. Fish were acclimatized in an aerated holding tank for two weeks and were fed with commercial Tetramin flakes ad libitum twice daily. An experimental tank with an inner glass visijar was prepared with dechlorinated tap water. After a stabilization period of seven days, 40 fish, measuring from $3.5-6.5 \mathrm{~cm}$, irrespective of sex, were randomly transferred from the holding tank to the outer area of the experimental tank. The feeding regimen for these fish was the same as that for those in the holding tank. The experiment was conducted after another acclimatization period of seven days.

At the start of the experiment, 32 fish were randomly transferred to the inner visijar and were deprived of food. The six remaining control fish in the outer area of the experimental tank were fed with commercial Tetramin flakes ad libitum twice daily as usual. The water in the inner visijar was replaced with dechlorinated, pre-stabilized water at short intervals to prevent coprophagy. Six starving fish were randomly sacrificed at intervals of 24, 48, 72 and 96 hours for histological studies. At the end of the experiment, the six control fish, fed throughout the experimental duration were also sacrificed for histological investigations.

The fish were placed in an ice bath and were immediately decapitated. Livers were dissected out, cut into small pieces and immediately fixed in Karnovsky fixative buffered with sodium cacodylate to $\mathrm{pH}$ of 7.4 for four hours at $4{ }^{\circ} \mathrm{C}$. The tissues were washed twice with sodium cacodylate and then kept in this buffer at $4{ }^{\circ} \mathrm{C}$. The tissues were then postfixed in a $1 \%$ aqueous solution of osmium tetroxide for 1 hour, dehydrated in a series of graduated concentrations of alcohol and embedded in Agar 100 resin.

Semi-thin and ultrathin sections were cut using an ultramicrotome using glass knives. The semi-thin sections were stained with $1 \%$ toluidine blue and the ultrathin sections were stained with super saturated uranyl acetate and lead citrate, and both were examined using a JEOL JEM-1230 TEM.

\section{Results}

A. dispar were able to survive food deprivation for over $96 \mathrm{hrs}$. However, after this time, some experimental fish became lethargic and others became moribund. Therefore, the experiments were terminated after the maximum set duration of 96 hours.

\section{a. Light Microscopy}

Semi-thin sections of the normally fed A. dispar showed the general structure of the liver. The liver is composed of a continuous compact layer of hepatocytes which are arranged in rays of cords surrounding the sinusoids and the central veins. The hepatocytes are polyhedral in shape and have round central nuclei (Figure 1).

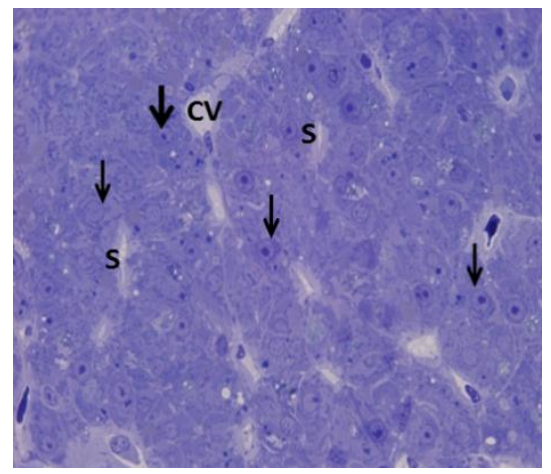

Figure 1. Light micrograph of normally fed A. dispar showing: normal structure of the liver; hepatocytes (arrows); sinusoid (S) and central vein (CV) X400. 
Some alterations to the liver structure were seen in the groups of fish starved for 24, 48, 72 and 96 hours (Figure 2). These alterations were in the form of vacuolation and degeneration of the liver tissue. The vacuolation and degeneration characteristics started to appear at 24 hours and became progressively more pronounced with the increase in the duration of starvation (Figure 2). These characteristics represent necrosis of the hepatocytes.
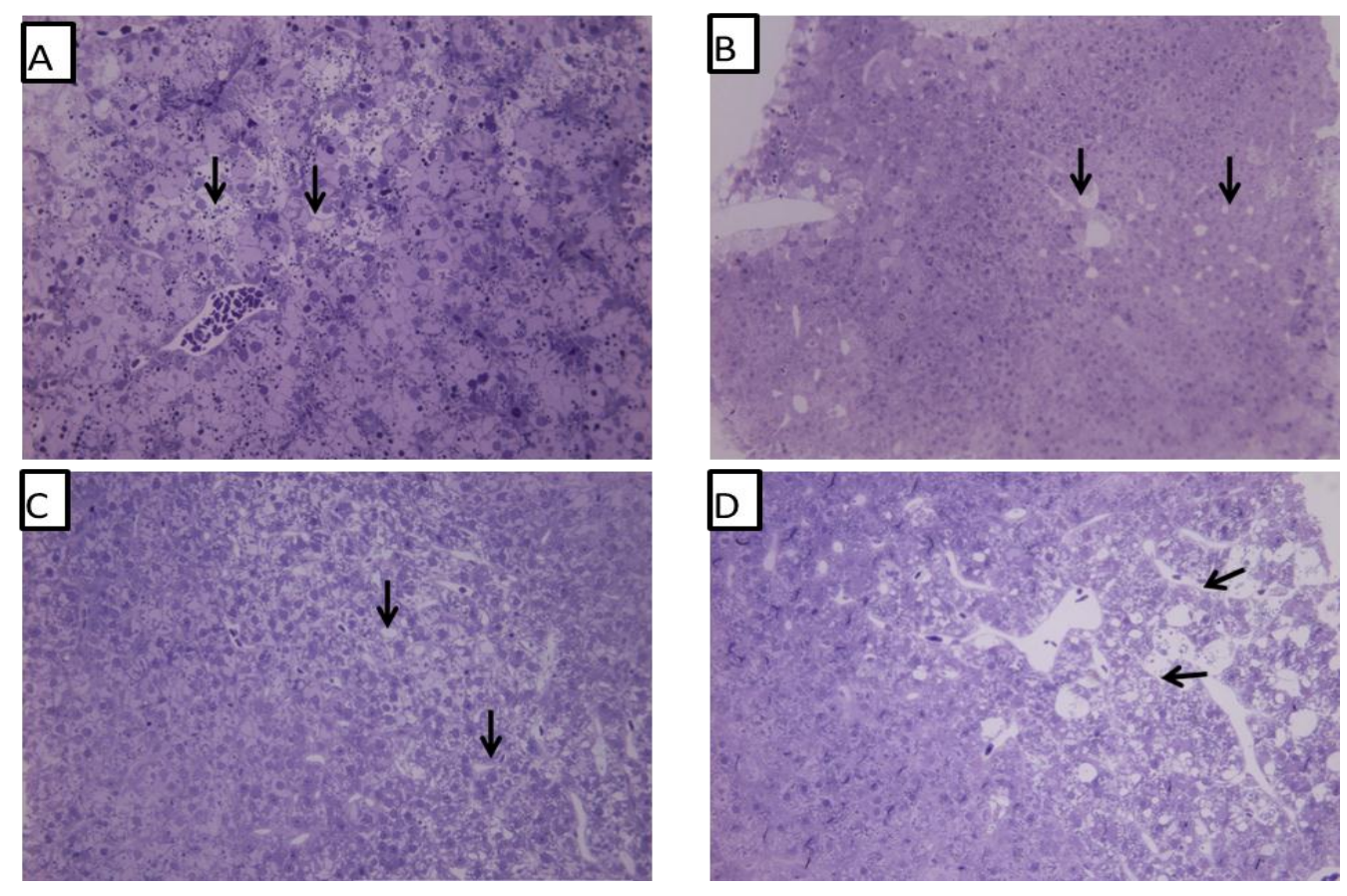

Figure 2. Light micrographs of saved A. dispar fish showing: (A) $24 \mathrm{hr}$, (B) $48 \mathrm{hr}$, (C) $72 \mathrm{hr}$, (D) $96 \mathrm{hr}$ with alterations of the liver structures, vacuolization (arrows) X400.

\subsection{Transmission Electron Microscopy}

The hepatocytes of the normally fed A. dispar showed polyhedral cells with centrally located round or ovoid nuclei. Some hepatocytes possessed nucleoli. The rough endoplasmic reticulum (RER) were arranged in parallel stacks of cisternae (Figure 3). The RER were seen around the nuclei in some cells and in others they were seen within the boundary of the cell membrane (Figure 3). The shape and size of mitochondria varied; some were elongated and others were rounded with well-developed cristae. The mitochondria were usually seen in association with RER (Figure 3).

In the starved groups, the hepatocytes showed ultrastructural alterations dependent on the duration of starvation. The prominent features in the liver of starved fish (starved for 24, 48,72 and 96 hours) were the condensation of RERs around the nuclei and the increase in the quantity of glycogen (Figures 4-7). The mitochondria were seen in association with RER and some of these were large and condensed. Lysosomes were also present (Figures 5B, 7B).
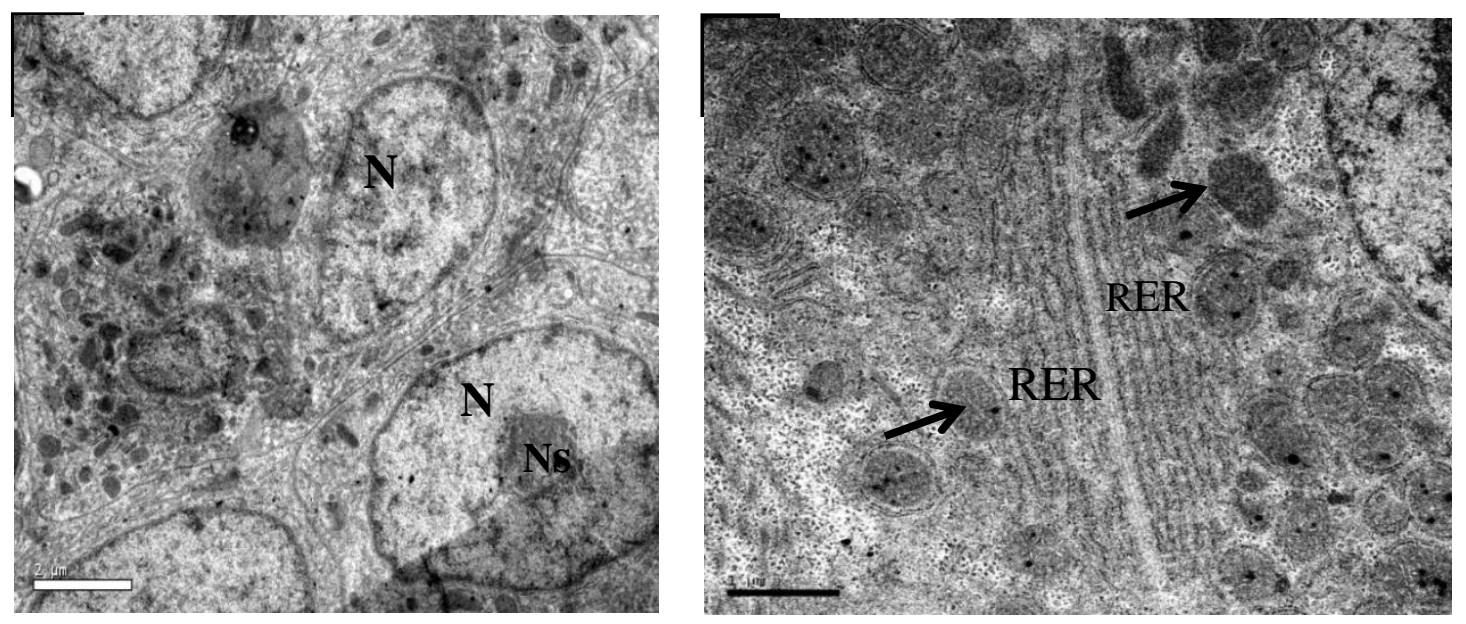

Figure 3. Electron micrograph of the normally fed A. dispar showing: normal nuclei (N), nucleolus (Ns), mitochondria (arrows), rough endoplasmic reticulum (RER). 

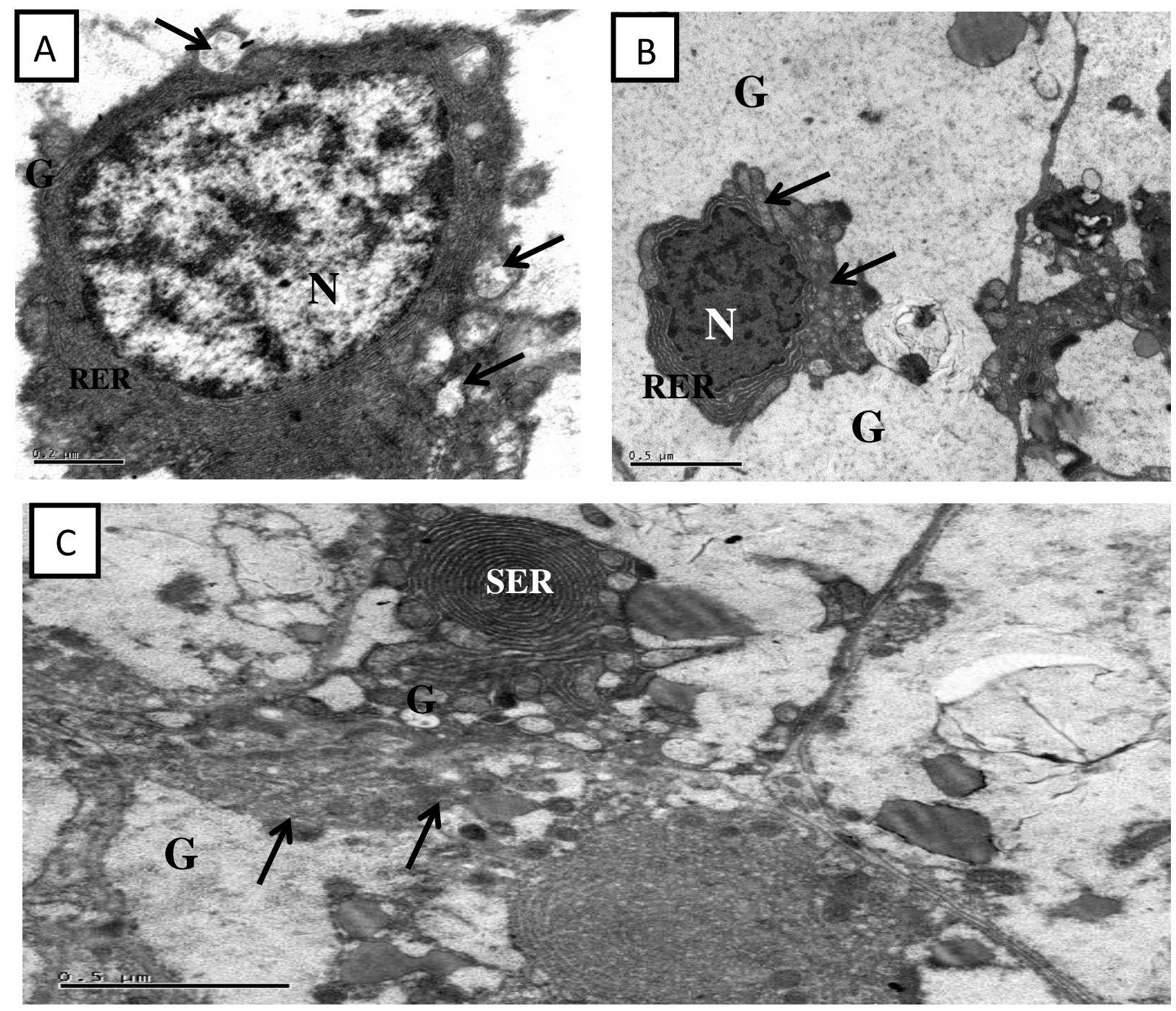

Figure 4. Electron micrographs of $24 \mathrm{hr}$ starved A. dispar (A - C) showing: nuclei (N), mitochondria (arrows) rough endoplasmic reticulum (RER), glycogen $(\mathrm{G})$ and swirls of smooth endoplasmic reticulum (SER).
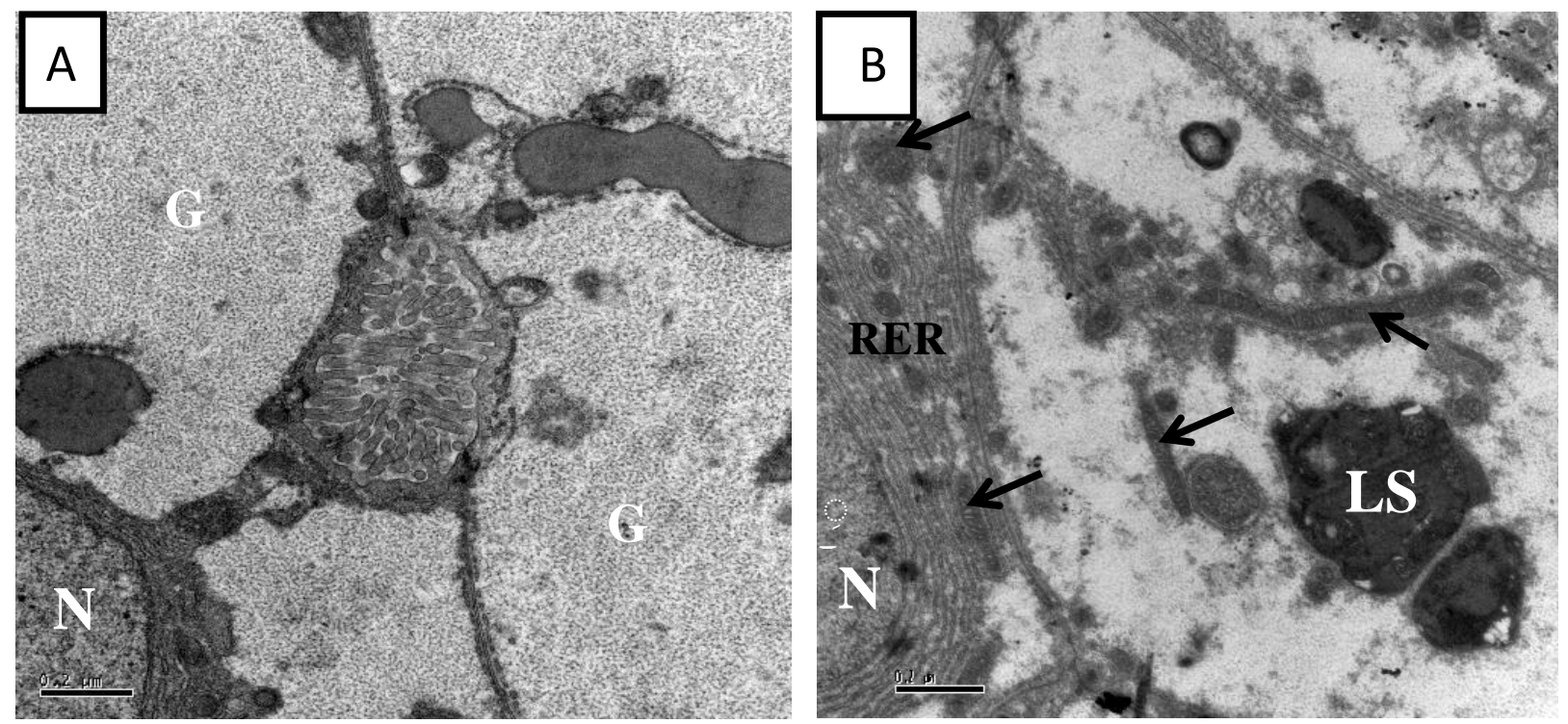

Figure 5. Electron micrographs of $48 \mathrm{hr}$ starved A. dispar (A \& B) showing: nuclei (N), mitochondria (arrows), rough endoplasmic reticulum (RER), glycogen (G) and lysosomes (LS). 

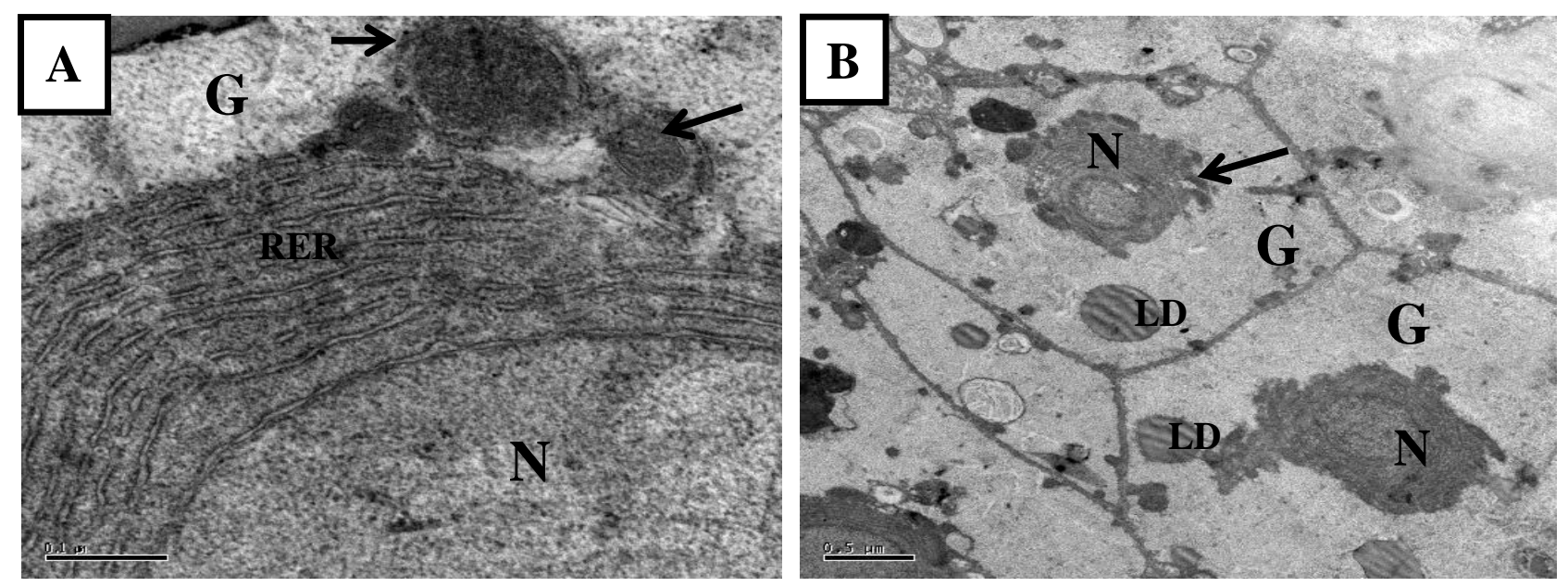

Figure 6. Electron micrographs of $72 \mathrm{hr}$ starved A. dispar (A \& B) showing: nucleus (N), mitochondria (arrows), rough endoplasmic reticulum (RER), glycogen (G) and lipid droplets (LD).
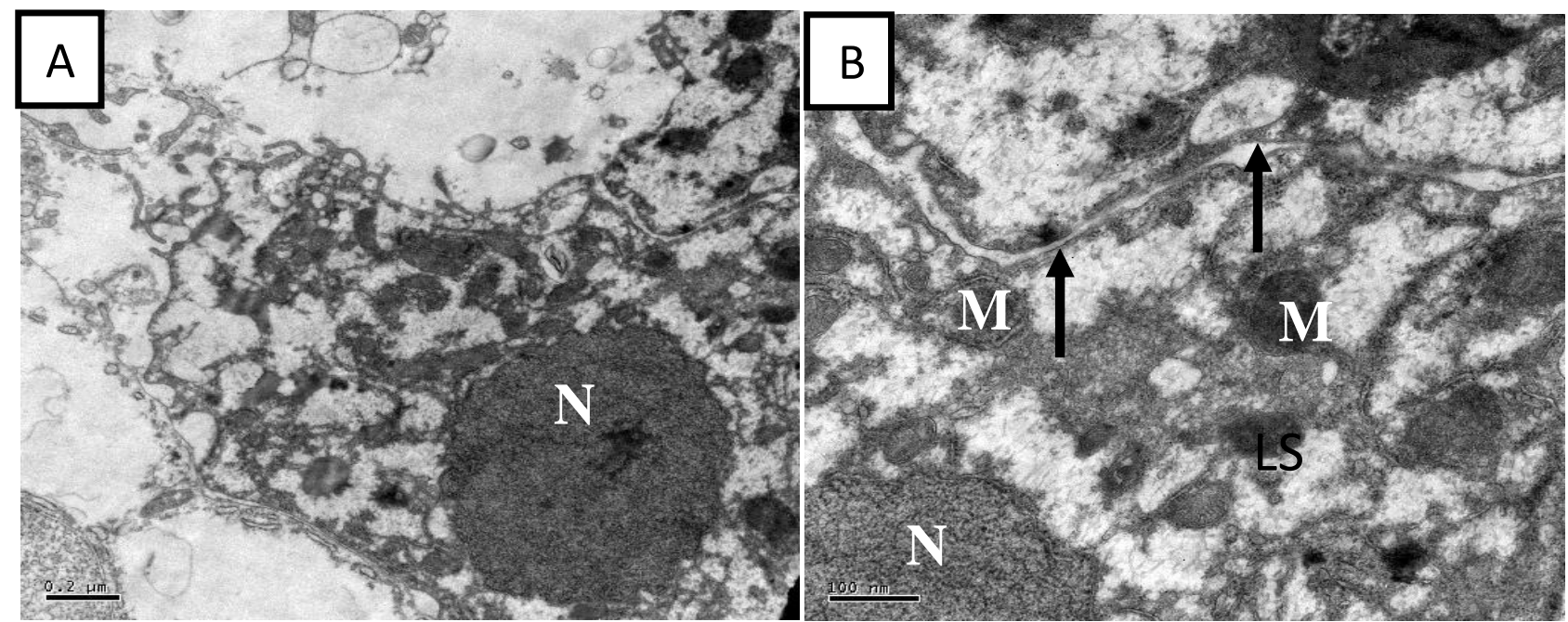

Figure 7. Electron micrographs of $96 \mathrm{hr}$ starved A. dispar fish (A \& B) showing: disintegration of the cytoplasmic organelles and shrinkage of nucleus (N) and intercellular space (arrows), lysosomes (LS) and mitochondria (M).

In the starved groups, the hepatocytes showed ultrastructural alterations dependent on the duration of starvation. The prominent features in the liver of starved fish (starved for 24, 48, 72 and 96 hours) were the condensation of RERs around the nuclei and the increase in the quantity of glycogen (Figures 4-7). The mitochondria were seen in association with RER and some of these were large and condensed. Lysosomes were also present (Figures 5B, 7B).

Some hepatocytes were characterized by chromatin condensation and shrinkage of their nuclei, and the presence of vacuoles (Figures 4B, 7A). They also had irregular-shaped nuclei with some being shrunken and folded (Figures 4B, 7A). Some cytoplasmic organelles, such as the mitochondria and SER had a bizarre appearance (Figures 4B,7A). Some cells had lost contact with their neighbors (Figure 7).

\section{Discussion}

This histological study looked at the effect of starvation on the liver of A. dispar and showed changes in its structure, both under light and transmission electron microscopy. Many empty spaces were observed in light micrographs and this could be correlated to the decrease in the size of hepatocytes or the breakdown of tissue by apoptosis caused by starvation. Many fish go through natural periods of starvation and consequently have to overcome starvation using biochemical, physiological, and behavioral strategies [6]. The effects of nutrient depletion during starvation are quite different in each fish organ [8]. Segner and Moller [14] showed a decrease in the size of the nucleus in the hepatocytes of the olive flounder as a result of starvation. However, these authors also showed that the re-feeding of this fish resulted in the enlargement of hepatocytes and the narrowing of intercellular spaces. 
The hepatocytes of $A$. dispar underwent those ultrastructural changes that have previously been described for other species [14]. Widened intercellular spaces are indicative of the decreasing size of some cells, where the diameter of the cell nucleus is reduced. There was also depletion of glycogen and lipid in the cell, condensation of chromatin material and depletion of ribosome-studded ER [15,6]. As seen in flounders, the starved A. dispar rapidly lost vitality after 96 hours of starvation. There were stark differences between the starved and fed groups. In the starved groups, cell junctions often were dissolved, except in those complexes surrounding bile canaliculi. This finding indicates metabolic dysfunction and disturbed communication at the tissue level [6].

The effects of starvation on the liver of juvenile flounders showed a decrease in stored products, reduction of endoplasmic reticulum, increased numbers of lysosomes and macrophages, proliferation of collagenous fibers and dissolution of cell junctions [14,6]. The results obtained in our study were similar to findings on the olive flounder in that the size of mitochondria increased due to starvation. Additionally, we observed the bizarre appearance of mitochondria and the SER.

Some hepatocytes showed cell death in the form of necrosis. From these results we can conclude that starvation has an effect on the structure of hepatocytes.

It is not uncommon to find large numbers of dead A. dispar in shallow wadi pools in any season. Post-mortem examination of the livers from these fish using histology may help to determine if there are other factors which produce similar effects to those of starvation. Therefore, future studies should look at the effect of other physical factors like temperature and chemical environment, including salinity, on the hepatocytes of $A$.dispar. The effect of hazardous substances like pesticides could also mimic the effect of starvation.

Ba-Omar and Victor [13] discussed the changes in the intestinal epithelium of A. dispar subjected to starvation and this study adds hepatocytes to the list of cells investigated. Studies $[16,13,12,17,18]$ have been steadily adding information on the biology of this small, but ecologically important fish which can serve as a biocontrol agent of mosquito larvae, as a candidate for bioassay in toxicological studies and also as an indicator of environmental impacts in aquatic ecosystems. Unfortunately, the introduction of exotic tilapia to natural water bodies in Oman is at present posing a serious threat to $A$. dispar (and also to two other species of freshwater fish) and a premature local extinction of this species is a serious possibility; this may put an end to the accumulation of knowledge on this ecologically versatile eurytopic fish.

\section{References}

1. Haas, R. Notes on the ecology of Aphanius dispar in the Sultanate of Oman. Freshwater Biol., 1982, 12, 8995.

2. Lotan, R. Sodium chloride and water balance in the euryhaline teleost Aphanius dispar (Cyprinodontidae). Zeits. Vergleisch. Physiol., 1969, 65, 455-462.

3. Lotan, R. Osmotic adjustment in the euryhaline teleost Aphanius dispar (Cyprinodontidae). Zeitsr. Vergleisch. Physiol., 1971, 75, 383-387.

4. Plaut, I. Resting metabolic rate, critical swimming speed, and routine activity of the euryhaline cyprinodontid, Aphanius dispar, acclimated to a wide range of salinities. Physiol. Biochem. Zool., 2000, 73(5), 590-596.

5. Storch, V. and Juario, J.V. The effect of starvation and subsequent re-feeding on the hepatocytes of Chanos chanos. Fish Biol., 1983, 23, 95-103.

6. Hur, J., Jo, J.H. and Park, I.S. Effects of long term starvation on hepatocyte ultrastructure of olive flounder Paralichthys olivaceus. Ichthyol Res., 2006, 53, 306-310.

7. Cunnane, S.C. Differential utilization of long chain fatty acids during triacylglycerol depletion. II. Rat liver after starvation. Lipids, 1988, 23(4), 372-374.

8. Hung, S.O., Liu, W., Li, H. and Storebaken, T. Effect of starvation on some morphological and biochemical parameters in white sturgeon, Acipenser transmontanus. Aquaculture, 1997, 151, 357-363.

9. Kristen, L., Wall, K.L. and Crivello, J. Effects of starvation on liver microsomal P450 activity in juvenile Pleuronectes americanus. Comp. Biochem. Physiol., Part C: Pharm. Toxicol. Endocr., 1999, 123, $273-277$.

10. Deng, L., Zhang, M., Lin, R, Christopher, H.K. and Cheng, C.H.K. Effects of food deprivation on expression of growth hormone receptor and proximate composition in liver of black sea bream Acanthopagrus schlegeli. Comp. Biochem. Physiol. Part B: Biochem. Mol. Biol., 2004, 137, 21-432.

11. Morales, E.A., Jiménez, A.B., Hidalgo, M.C., Abellán, E. and Cardenete, G. Oxidative stress and antioxidant defenses after prolonged starvation in Dentex dentex liver. Comp. Biochem. Physiol., 2004, 139, $153-161$.

12. Ba-Omar, T.A., Victor, R. and Tobias, D.B. Some aspects of the anatomy of and histology of the digestive tracts in two sympatric species of freshwater fishes. SQU J. Scientific Res.- Sci. \& Tech., 2003, 8, 97-106.

13. Ba-Omar, T.A. and Victor, R. Ultrastructural changes in the epithelium of the stomach of Aphanius dispar (Cyprinodontidae), due to stress from starvation. SQU J. Scientific Res.- Sci. \& Tech., 2000, 5, 1-9.

14. Segner, H. and Moller, H. Electron microscopical investigations on starvation induced liver pathology in flounders Platichthys flesus. Mar. Ecol. Prog. Ser., 1984, 19, 193-196. 
TAHER A. BA-OMAR ET AL

15. Moon, T.W. and Johnston, J.A. Amino acid transport and inter-conversions in tissues of freshly caught and food-deprived plaice, Pleuronectes platessa L. J. Fish Biol., 1981, 19, 653-663.

16. Ba-Omar, T.A., Victor, R. and Tobias, D.B. Histology of the stomach of Aphanius dispar (Ruppell 1828), a cyprinidont fish, with emphasis on change caused by stress from starvation. Trop. Zoo., 1998, 11, 11-17.

17. Ba-Omar, T.A., Al-Jardani, S. and Victor, R. Effects of pesticide temephos on the gills of Aphanius dispar (Pisces: Cyprinodontidae). Tissue and Cell, 2011, 43, 29-38.

18. Al-Ghanbousi, R., Ba-Omar, T.A. and Victor, R. Effect of deltamethrin on the gills of Aphanius dispar: A microscopic study. Tissue and Cell, 2012, 44, 7-14.

Received 1 May 2013

Accepted 3 November 2013 